\title{
Mechanical and microstructural properties of Cameroonian CPJ NC CEM II/B-P 42.5R cement substitution by glass powder in the cement paste and mortar
}

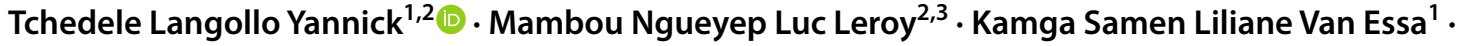 \\ Tchamba Arlin Bruno ${ }^{1,4} \cdot$ Ngounouno Ismaïla $^{5}$. A. Bier Thomas ${ }^{4}$
}

Received: 23 March 2020 / Accepted: 25 June 2020 / Published online: 13 July 2020

(c) Springer Nature Switzerland AG 2020

\begin{abstract}
The present study deals with the mechanical and microstructural properties of CPJ NC CEM II/B-P 42.5R cement mortar with glass powder $(\phi<80 \mu \mathrm{m})$ substitution. Three types of glass powders were used as cement additive from 0 to $25 \mathrm{wt} \%$ with $5 \mathrm{wt} \%$ interval. These were white glass powder (WGP), green glass powder (GGP), brown glass powder (BGP) and their mixture (MGP). The physical properties of the cement paste show an increase in setting time from 240 min for OPC to $290 \mathrm{~min}$ for $25 \mathrm{wt} \%$ addition of all glass powder types. The compressive strength of the cement mortar after 28 days increased from 21.5 MPa for the OPC to $23.5 \mathrm{MPa}, 26.2 \mathrm{MPa}, 24.4 \mathrm{MPa}$ and 24.0 MPa for $10 \mathrm{wt} \%$ addition of WGP, GGP, BGP and MGP, respectively. By cons, the compressive strength decreased from these values to $21.3 \mathrm{MPa}$ for $25 \mathrm{wt} \%$ addition of WGP, GGP on the one hand and $21.5 \mathrm{MPa}$ for $25 \mathrm{wt} \%$ addition of BGP, MGP on the other hand. Up to $20 \mathrm{wt} \%$ addition, compressive strength of cement mortar containing glass powder was greater than ordinary Portland cement (OPC) mortar. Further analysis was performed on the cement paste from 0 to $15 \mathrm{wt} \%$ glass powder addition. The infrared spectroscopy (FTIR) was used to analyse the surface functional groups of different samples. The X-ray diffractometry analysis revealed the presence of gypsum, portlandite, calcium carbonate, ettringite, $\mathrm{C}-\mathrm{S}-\mathrm{H}$, di-calcium aluminate, tetra-calcium alumina ferrite minerals and sodium carbonate resulting from the glass powder addition on all samples. The intensity of portlandite was reduced by the addition of glass powder, suggesting its consumption due to pozzolanic reaction. Scanning electron microscopy images exhibited the excess of micropores when glass powder contents increased, explaining a decrease in compressive strength of mortars from 10 to $25 \mathrm{wt} \%$ addition of glass powder. From these results, regardless of the colour of glass, the optimum percentage substitution of CPJ NC CEM II/B-P 42.5R cement by glass powder in a mortar, considering mechanical properties, is $10 \mathrm{wt} \%$.
\end{abstract}

Keywords Addition · Glass powder · Cement · Flexural strength · Compressive strength · Microstructure

$\triangle$ Tchedele Langollo Yannick, yannicktl@yahoo.com | ${ }^{1}$ Research Department, Local Materials Promotion Authority (MIPROMALO), Yaoundé, Cameroon. ${ }^{2}$ Department of Mining Engineering, School of Geology and Mining Engineering, University of Ngaoundere, Meiganga, Cameroon. ${ }^{3}$ Laboratory of Material Sciences, Department of Physics, Faculty of Sciences, University of Yaounde 1, Yaoundé, Cameroon. ${ }^{4}$ Institut für keramik, glas und Baustofftechnik, Technical University of Freiberg, Freiberg, Germany. ${ }^{5}$ Department of Mining Geology, School of Geology and Mining Engineering, University of Ngaoundere, Meiganga, Cameroon. 


\section{Introduction}

The environmental considerations have taken an unprecedented scale worldwide. One of the most important issues to be solved is waste management; the most appropriate way of doing this is recycling. As the cement industry is known to be highly polluting ( 1 tonne of $\mathrm{CO}_{2}$ emitted per $1 \mathrm{t}$ of clinker produced [1]), the use of mineral waste as cement additives could be a convincing solution. In this regard, the American Society for Testing Materials (ASTM), among others, has defined the class of supplementary cementitious materials with the objectives of reducing the consumption of cement on the one hand (with a direct effect on the reduction of $\mathrm{CO}_{2}$ emissions [1]) and the improvement in the concrete properties on the other hand through the pozzolanic reactions. Thus, work on blast furnace slag, fly ash, silica fume, fine limestone, natural pozzolan and calcined schist was conclusive and standardized [2].

Glass, because of its amorphous nature and its relatively high contents in silica, was generally considered to be pozzolanic when finely grounded. Thus, it could be used as a partial replacement for Portland cement in mortars and concretes [3-7]. Several works [8-10] were conducted in the last decade on the use of glass as aggregates in concrete. However, these works reported that all concretes were inflated and cracked. Since then, the idea has been partly abandoned.

The subject has become relevant again for a number of years. Indeed, for economic and environmental reasons, the use of recycled glass in cements and concretes has attracted the interest of innumerable decision-makers and these have encouraged new studies [11-17]. Researchers have investigated on glasses that can be used in a cement matrix and have identified them as sodo-calcic and lead glasses [18]. Other researchers have investigated on the size of glass grains; a size of $75 \mu \mathrm{m}$ would be sufficient to achieve a good index of pozzolanic activity $[19,20]$. Research also concerned the glass content in the cement matrix. Some studies $[7,17,21]$ have shown that mechanical strength of cementitious materials increased with the content of glass mixtures. Most of other works, despite the variation in working conditions, agree that the strength of mortars and concretes decreased as their glass content increased [22-24]. With regard to the colour of glass, investigation has been directed towards the expansion due to three different colours of glass and has shown that it varies according to the colour [25-27].

Accordingly, the present work consists in determining the mechanical and microstructural behaviour of the ordinary Portland cement (OPC) mortar with the addition of three different colours of ground glasses and their mixture.
To achieve this objective, different glass types will be used as cement additives from 0 to $25 \mathrm{wt} \%$ with $5 \mathrm{wt} \%$ interval in turn to highlight the flexural and compressive strengths of the mortars at 2, 7 and 28 days. Furthermore, the surface functional groups of the cement pastes, for the formulations giving the best mechanical strengths, will be determined performing infrared spectroscopy (FTIR) at 21 days. The hydrated mineral products will be identified executing X-ray diffractometry (XRD) at 21 days. The microstructural structures of the formulated cement pastes will be exhibited by performing scanning electron microscopy (SEM) coupled with energy-dispersive X-ray (EDS), on the same samples used for FTIR and XRD, at the same age.

\section{Materials and methods}

\subsection{Materials}

\subsubsection{The glass powders}

To carry out this work, three types of glasses with different colours and their mixture were collected from the SOCAVER drink bottle wastes and prepared to be used as cementitious additions. The bottles were cleaned, crushed, ground and sieved to the particle size of about $80 \mu \mathrm{m}$. The samples obtained were white glass powder (WGP), green glass powder (GGP), brown glass powder (BGP) and mixed glass powder (MGP).

\subsubsection{The cement}

The cement used is CPJ-CEM II/B 42.5R according to the standard NC 234: 2009-06, of Cimaf brand. It is manufactured by the company Ciment d'Afrique (Cimaf), based in Douala at Bonaberi, and marketed in a $50-\mathrm{kg}$ bag. The physico-mechanical characteristics are a compressive strength of $25 \mathrm{MPa}$ after 2 days, $35 \mathrm{MPa}$ after 7 days and $45 \mathrm{MPa}$ after 28 days. The specific area is $3425 \mathrm{~cm}^{2} / \mathrm{g}$ with a consistency of $29 \%$. The bulk density is $950 \mathrm{~kg} / \mathrm{m}^{3}$. This cement is named in the current study ordinary Portland cement (OPC).

\subsubsection{Sand}

The sand used is from the banks of the Sanaga River. It was washed through the sieves of an $80-\mu \mathrm{m}$ screen to remove the fine particles. The sand was dried in an oven for $24 \mathrm{~h}$ at $105^{\circ} \mathrm{C}$ and sieved in different fractions with respect to the European Committee of Standardization (CEN) for normal sand. The resulting grain size curve is presented in Fig. 1. 


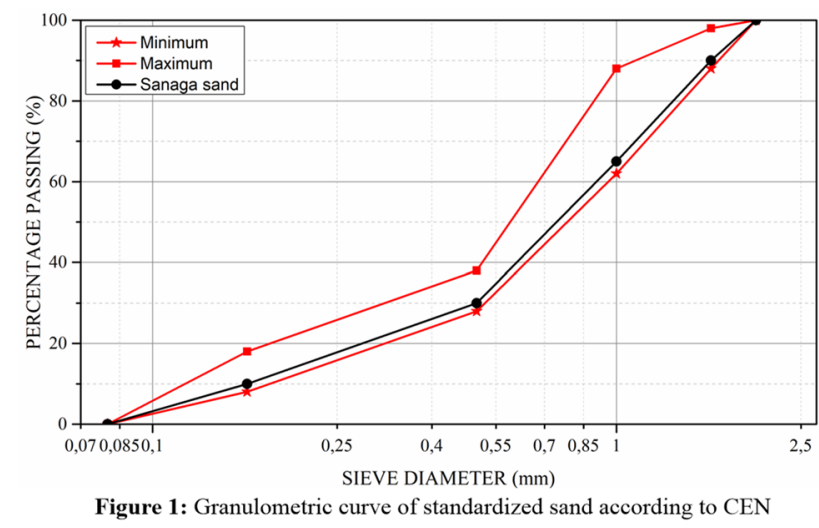

Fig. 1 Granulometric curve of standardized sand according to CEN

\subsection{Methods}

\subsubsection{X-ray fluorescence spectrometry (XRF)}

For XRF analysis, a hXRF Niton XL3t980 analyser (equipped with an $\mathrm{Ag}$ anode $50 \mathrm{kV} \mathrm{X-ray} \mathrm{tube} \mathrm{and} \mathrm{sili-}$ con drift detector 8-mm spot) was used. The raw data were plotted in spectra, where $x$-axes represent elementspecific fluorescence energy (unit keV) and y-axes quantify counts of photons (unit cps) received by the detector. Detection is possible for most of the elements with atomic numbers ranging from 12 (magnesium) to 92 (uranium). A 21 silicon-based standards so-called Certified Reference Material (CRM), filled in cups and covered with $4-\mu \mathrm{m}$ polypropylene film were measured by $\mathrm{hXRF}$ device specific mode (mining/mineral mode). The measured values were plotted using a trend line equation, and the "fitting coefficient" $R^{2}$ (correlation coefficients) were determined. Afterwards, a classification was made according to the quality of the regression line and the distribution of the data. XRF were performed on the glass powders.

\subsubsection{Production of mortar samples}

The mortar samples were made according to EN 196-1 with dimensions of $4 \times 4 \times 16 \mathrm{~cm}$. From the formulation of the normal mortar, at $W / C=0.45$, the cement was substituted at $0 \mathrm{wt} \%$ (OPC), $5 \mathrm{wt} \%, 10 \mathrm{wt} \%, 15 \mathrm{wt} \%, 20 \mathrm{wt} \%$ and $25 \mathrm{wt} \%$ by different glass powders (GGP, WGP, BGP and MGP), to obtain the different formulations. Three samples of each formulation were used for both flexural strength test and compressive strength test. A total of 189 prismatic mortar specimens were produced. The quantities used are found in Table 1.
Table 1 Composition of mortar tested samples

\begin{tabular}{lcccc}
\hline $\begin{array}{l}\text { \% of replace- } \\
\text { ment (wt\%) }\end{array}$ & OPC (g) & $\begin{array}{l}\text { Glass } \\
\text { powder } \\
(\mathrm{g})\end{array}$ & Normal sand (g) & Water (g) \\
\hline 0 & 500 & 0 & 1350 & 225 \\
5 & 475 & 25 & 1350 & 225 \\
10 & 450 & 50 & 1350 & 225 \\
15 & 425 & 75 & 1350 & 225 \\
20 & 400 & 100 & 1350 & 225 \\
25 & 375 & 125 & 1350 & 225 \\
\hline
\end{tabular}

\subsubsection{Setting time}

The setting time test is performed with the Vicat apparatus on the cement paste at normal consistency. The initial setting time is the time from the beginning of mixing of the cement paste until the Vicat needle is stopped at a distance $d$ from the bottom of the mould loaded with $500 \mathrm{~g}$ of paste and such that $d=4 \pm 1 \mathrm{~mm}$. The final setting time is the time after which the end of setting time needle only sinks by $0.5 \mathrm{~mm}$. This test is carried out in accordance with Standard EN 196-3.

\subsubsection{Mechanical tests}

The flexural strength test was carried out on three $4 \times 4 \times 16 \mathrm{~cm}$ prismatic mortar specimens, for each formulation, at 2, 7 and 28 days of cure. At the end, the strength allowed is the average of the three values obtained. This test is performed according to EN 196-1 using the formula (Eq. 1):

$R_{t}=\frac{1,5 \times P \times L}{b^{3}}$

where $R_{t}=$ flexural strength $\mathrm{MPa}, L=$ distance between the lower support in $\mathrm{mm}, P=$ breaking load in $\mathrm{N}, b=$ thickness of the specimen $(b=40 \mathrm{~mm})$.

The compressive strength test is carried out on each half of the specimen used for the flexural test at the same dates, in accordance with NF-P-15-301 and ENV 197-1. The strength allowed is also the average of the values obtained. The compressive strength is calculated using the formula (Eq. 2):

$R_{\mathrm{c}}=\frac{P}{S}$

with $R_{\mathrm{c}}=$ compressive strength $\mathrm{MPa}, P=$ breaking load $\mathrm{N}$, $S=$ specimen section in $\mathrm{mm}^{2}\left(S=1600 \mathrm{~mm}^{2}\right)$. 


\subsubsection{Infrared spectroscopy}

Infrared spectroscopy (FTIR; using an Avatar 330, Thermo Nicolet) was performed on selected samples analysing surface and bulk areas. A minimum of 32 scans between 4000 and $400 \mathrm{~cm}^{-1}$ were averaged for each spectrum with $1 \mathrm{~cm}^{-1}$ resolution. The analysis was performed on the ordinary Portland cement paste and the mixtures of cement pastes with glass powder addition showing the best mechanical results (5 wt\%, $10 \mathrm{wt} \%$ and $15 \mathrm{wt} \%$ ). FTIR was used to analyse the surface functional groups of different samples after 21 curing days according to XRD and SEM analysis day curing.

\subsubsection{X-ray diffractometry (XRD)}

XRD measurements were performed using a D8 BrukerAXS diffractometer equipped with Lynx eye position sensitive detector, with $\mathrm{Cu} \mathrm{Ka} \kappa \mathrm{Cu}=1.54056 \AA$. radiation operated at $40 \mathrm{kV}$ and $40 \mathrm{~mA}$, increment $0.013^{\circ} 2 \theta$, and a measuring time per step of $30 \mathrm{~s}$. The diffraction patterns were collected in the 2-theta range from $7.5^{\circ}$ to $90^{\circ}$. Qualitative analysis of the phase composition of the powder samples was conducted using the PDF-2 2007 release software and X'Pert HighScore Plus. XRD was performed on the cement pastes containing $0 \mathrm{wt} \%, 5 \mathrm{wt} \%, 10 \mathrm{wt} \%$ and 15 wt\% of glass powder, after 21 curing days, to identify the hydrated products.

\subsubsection{Scanning electron microscopy (SEM)}

The grain size, surface topology and pore diameter nature of the hydrated cement were determined using an XL30 series Philips scanning electron microscope XL30 ESEM FEG (Fa, FEE) equipped with an energy-dispersive analyser (EDS), EDAX, Fa Annatet with GENESIS software, run at $10 \mathrm{kV}$ and at a resolution of 500-7500. The SEM images on OPC paste and cement paste with glass powder addition samples have been done after curing age of 21 days. SEM was performed on the same samples used for FTIR and XRD to confirm identification of hydrated products using different methods.

\section{Test results and discussion}

\subsection{X-ray fluorescence spectrometry (XRF)}

XRF was performed on the glass powders. The chemical composition obtained is given in Table 2 .

These results showed variation in the content of $\mathrm{Cr}_{2} \mathrm{O}_{3}$ and $\mathrm{Fe}_{2} \mathrm{O}_{3}$ from one glass compared to another, responsible for the colouring of the glasses. The content of $\mathrm{Cr}_{2} \mathrm{O}_{3}$
Table 2 Chemical composition of glass

\begin{tabular}{lccc}
\hline Elements & Brown (wt\%) & White (wt\%) & Green (wt\%) \\
\hline $\mathrm{SiO}_{2}$ & 72.48 & 72.12 & 72.15 \\
$\mathrm{Al}_{2} \mathrm{O}_{3}$ & 0.93 & 1.18 & 0.98 \\
$\mathrm{Fe}_{2} \mathrm{O}_{3}$ & 0.02 & 0.02 & 0.16 \\
$\mathrm{CaO}$ & 10.98 & 10.92 & 10.93 \\
$\mathrm{MgO}$ & 1.27 & 1.26 & 1.31 \\
$\mathrm{Na}_{2} \mathrm{O}$ & 13.83 & 13.90 & 13.77 \\
$\mathrm{~K}_{2} \mathrm{O}$ & 0.04 & 0.04 & 0.04 \\
$\mathrm{TiO}_{2}$ & 0.13 & 0.13 & 0.14 \\
$\mathrm{BaO}$ & 0.20 & 0.17 & 0.20 \\
$\mathrm{Cr}_{2} \mathrm{O}_{3}$ & 0.00 & 0.00 & 0.20 \\
$\mathrm{SeO}_{2}$ & 0.00 & 0.00 & 0.00 \\
$\mathrm{CoO}$ & 0.00 & 0.00 & 0.00 \\
$\mathrm{SO}_{3}$ & 0.11 & 0.26 & 0.11 \\
\hline
\end{tabular}

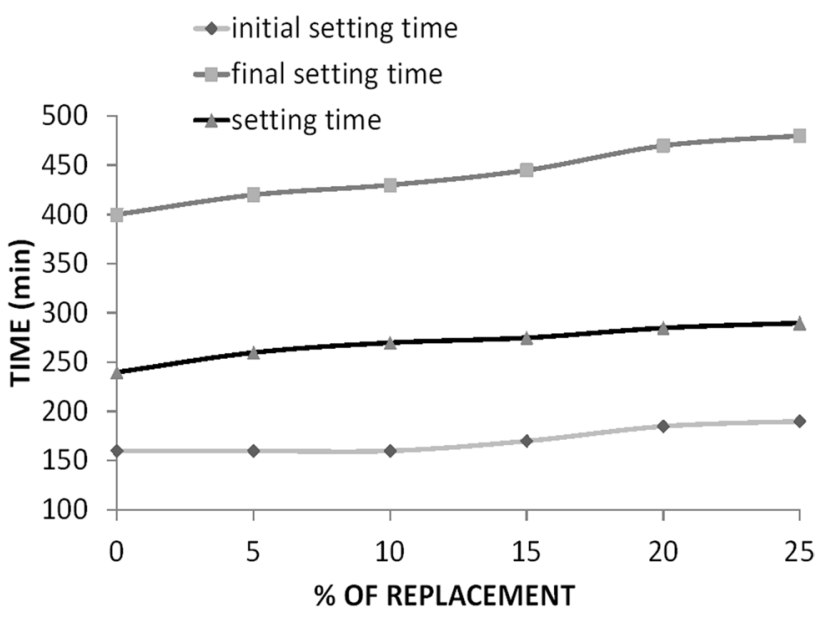

Fig. 2 Setting time of the cement paste for different percentages addition of glass powder

and $\mathrm{Fe}_{2} \mathrm{O}_{3}$ gradually increased from clear glass to brown glass. The $\mathrm{SO}_{3}$ content decreased from clear glass to brown glass. These compounds are in very small quantities in front of $\mathrm{SiO}_{2}$. Indeed, for all the glasses used, there is a high content of amorphous $\mathrm{SiO}_{2}$ (around 72\%), which suggests good pozzolanic behaviour that analysis would highlight. It is also necessary to note relatively high contents of $\mathrm{CaO}$ and $\mathrm{Na}_{2} \mathrm{O}, \mathrm{CaO}$ being a compound favouring the pozzolanic reaction.

\subsection{Setting time}

The setting time test was carried out with the Vicat apparatus in accordance with standard EN 196-3. Figure 2 shows the results of the initial setting time, the final setting time and then the setting time obtained on each glass powder substitution. 
It appears that the addition of glass powder has an effect of increasing the initial setting time, the final setting time and the setting time of the samples tested. In fact, the initial setting time is $160 \mathrm{~min}$ for the OPC, while with the addition of glass powder, it increases up to $200 \mathrm{~min}$ at $25 \mathrm{wt} \%$ of WGP, BGP, GGP and MGP. Regarding the final setting time, it increases from $400 \mathrm{~min}$ for the OPC to 480 min with the addition of $25 \mathrm{wt} \%$ of all glass powder types. Accordingly, the setting time obtained is $240 \mathrm{~min}$ for the OPC and increases to $290 \mathrm{~min}$ with the addition of $25 \mathrm{wt} \%$ glass powder. Lui et al. [3] reported an increase in the initial setting time and the final setting with the percentage of addition of glass powder. Indeed, their work demonstrated that the initial setting time increases from 291 to $341 \mathrm{~min}$ for the samples tested, while the final setting time increased from 450 to 534 min with scores up to $1036 \mathrm{~min}$ for $60 \%$ substitution by weight of cement by glass powder.

A high alkali content generally results in a rapid setting time [11]. But in this case, the setting time increases. This may be due to the fact that alkaline dissolution of glass powder is not fast enough and then has a limited influence on the initial hardening process [12]. On the one hand, the relatively long setting time is due to the dispersion of the cement grains and therefore influences their hydration, since the cement is replaced by recycled glass powder [13]. On the other hand, the pozzolanic reaction shows limited activity at early age [12], because glass colour has no effect on the setting time. In addition, with the increasing incorporation of glass powder, the water/cement ratio $(W / C)$ increased, and a higher amount of water therefore induced a longer hardening process. As a consequence, the addition of recycled glass powder increases at the same time the initial setting time, the final setting time and in fact the setting time.

\subsection{Mechanical tests}

Figures 3 and 4 depict flexural strength and compressive strength, respectively. They were performed after 2, 7 and 28 curing days, according to EN 196-1 standard.

As a result, the addition of glass powder in different colours in the cement paste up to $20 \mathrm{wt} \%$ usually increased the mechanical strength. This increase in strength is
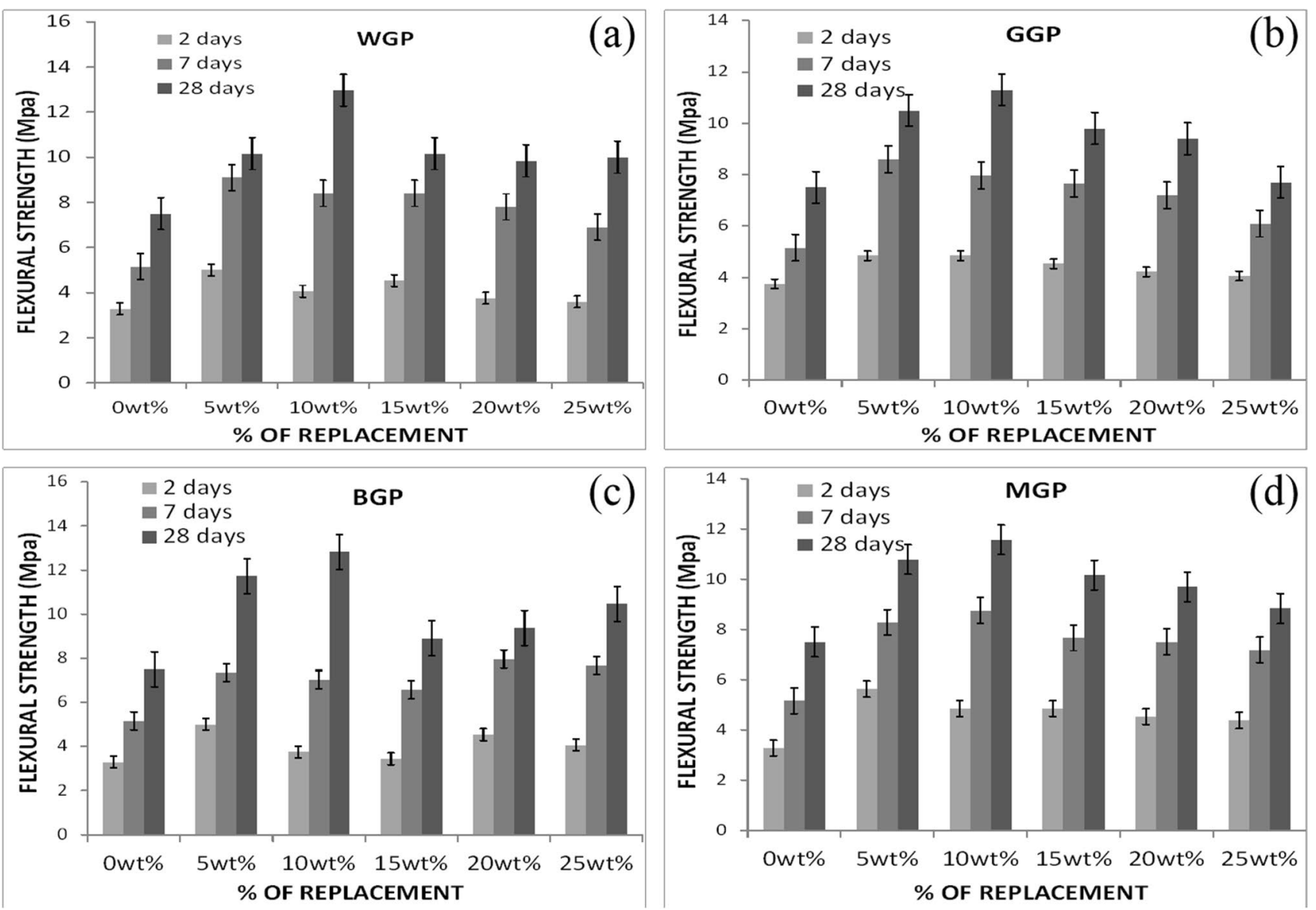

Fig. 3 Flexural strengths for the addition of a WGP, $\mathbf{b}$ GGP, $\mathbf{c}$ BGP, $\mathbf{d}$ MGP on the mortar specimens 

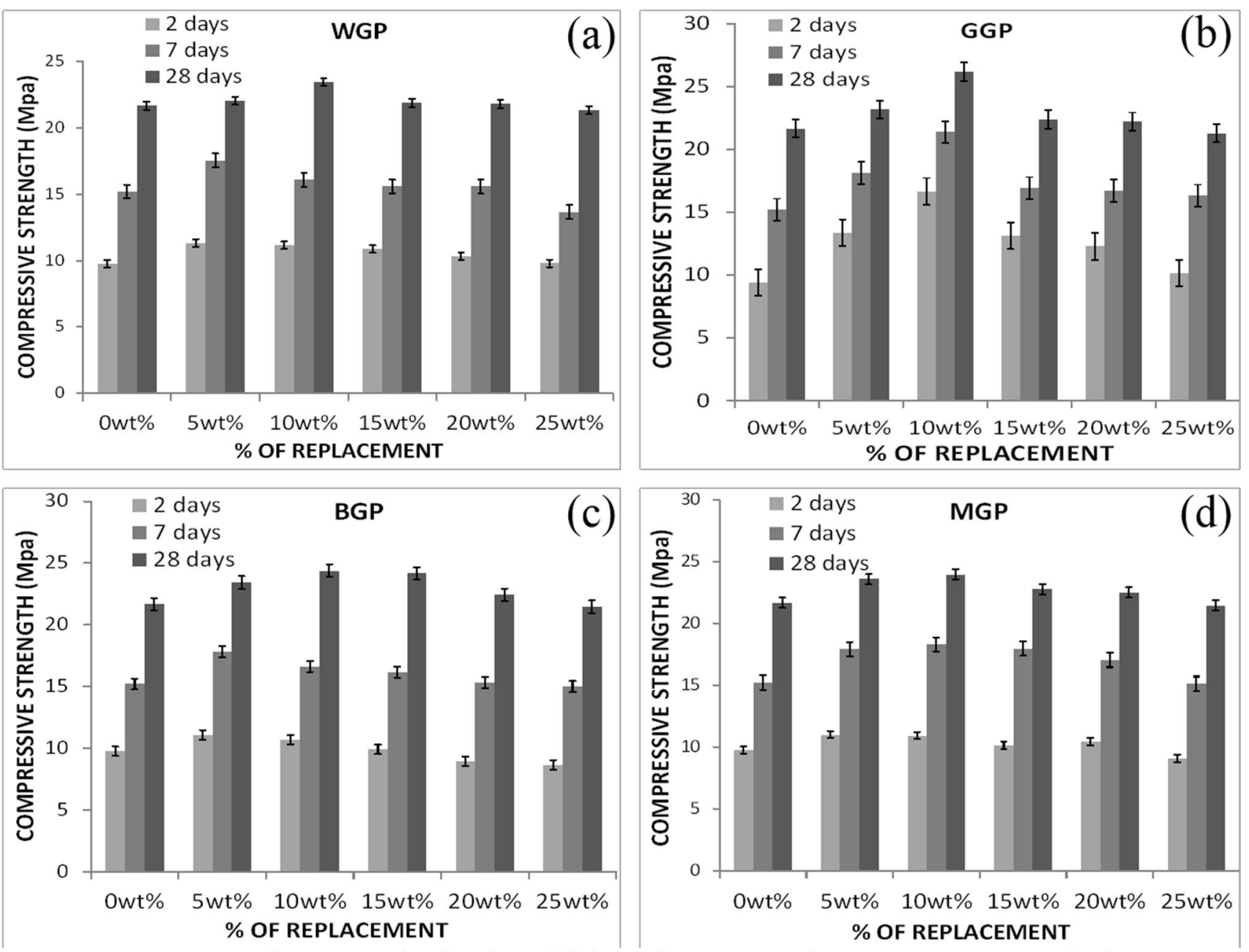

Fig. 4 Compressive strengths for the addition of a WGP, $\mathbf{b}$ GGP, $\mathbf{c}$ BGP, $\mathbf{d}$ MGP on the mortar specimens

affected by the rate of glass powder. For the flexural test on mortars samples after 28 curing days, the addition of WGP increases strength up to $72.92 \%$ from the control sample (OPC). For GGP, the addition improves strength up to $50 \%$. For the BGP addition, strength increases by $70.83 \%$ and increases by $54.17 \%$ with the addition of MGP. These optimal percentages are obtained each time at 10 wt $\%$ substitution for each type of glass with standard deviations of $17.56 \%, 18 \%, 21.62 \%$ and $13.89 \%$, respectively, for WGP, GGP, BGP and MGP additions, respectively. The exhaustive results of the comparison among OPC and the addition of glass powder are summarized in Table 3. Regarding compressive strength of samples at age 28 days, the addition of WGP, GGP, BGP and MGP increases the strength to maximum values, respectively, of the order of $8.27 \%$, $20.77 \%, 12.50 \%$ and $10.58 \%$. These maximum strengths are all identified at $10 \mathrm{wt} \%$ substitution for all glass colours with standard deviations of $3.71 \%, 8.63 \%, 5.65 \%$ and $4.52 \%$, respectively, for WGP, GGP, BGP and MGP additions,
Table 3 Variations in flexural strengths of mortar at 28 days compared with the control sample

\begin{tabular}{lllll}
\hline \% of replacement & \multicolumn{4}{l}{$\begin{array}{l}\text { Variations of flexural strength with } \\
\text { glass powder addition on mortar at } \\
\text { 28 days (\%) }\end{array}$} \\
\cline { 2 - 5 } & WGP & GGP & BGP & MGP \\
\hline 5 & 35.42 & 40.00 & 56.25 & 43.75 \\
10 & 72.92 & 50.67 & 70.83 & 54.17 \\
15 & 35.42 & 30.67 & 18.75 & 35.42 \\
20 & 31.25 & 25.33 & 25 & 29.17 \\
25 & 33.33 & 2.67 & 39.58 & 17.71 \\
Standard deviation $(\sigma)$ & 17.56 & 18.00 & 21.62 & 13.89 \\
\hline
\end{tabular}

respectively. Table 4 presents compressive strength changes compared to the control sample strength.

Without any additive in cement paste, the classic mechanism involves hydration of cement calcium silicates $\left(C_{2} S\right.$ 
Table 4 Variations in compressive strengths of mortar at 28 days compared with the control sample

\begin{tabular}{lrrrr}
\hline \% of replacement & \multicolumn{4}{l}{$\begin{array}{l}\text { Variations in compressive strength of } \\
\text { mortar at 28 days with glass powder } \\
\text { addition (\%) }\end{array}$} \\
\cline { 2 - 5 } & WGP & GGP & \multicolumn{1}{c}{ BGP } & MGP \\
\hline 5 & 1.73 & 6.92 & 8.08 & 8.85 \\
10 & 8.27 & 20.77 & 12.50 & 10.58 \\
15 & 0.96 & 3.27 & 11.54 & 5.00 \\
20 & 0.58 & 2.50 & 3.46 & 3.85 \\
25 & -1.54 & -1.73 & -0.96 & -0.96 \\
Standard deviation $(\sigma)$ & 3.71 & 8.63 & 5.65 & 4.52 \\
\hline
\end{tabular}

or/and $\left.\mathrm{C}_{3} \mathrm{~S}\right)$ to form hydrated calcium silicates $(\mathrm{C}-\mathrm{S}-\mathrm{H})$ of the "1st generation". This process leads to hardening of the cement following the equations (Eqs. 3, 4):

$$
\begin{aligned}
& \underset{\mathrm{C}_{3} \mathrm{~S}}{2\left(3 \mathrm{CaO} \cdot \mathrm{SiO}_{2}\right)}+\underset{\text { water }}{6 \mathrm{H}_{2} \mathrm{O}} \underset{\mathrm{C}-\mathrm{S}-\mathrm{H}}{3 \mathrm{CaO} \cdot 2 \mathrm{SiO}_{2} \cdot 3 \mathrm{H}_{2} \mathrm{O}}+\underset{\text { portlandite }}{3 \mathrm{Ca}(\mathrm{OH})_{2}} \\
& 2\left(2 \mathrm{CaO} \cdot \mathrm{SiO}_{2}\right)+6 \mathrm{H}_{2} \mathrm{O} \longrightarrow 3 \mathrm{CaO} \cdot 2 \mathrm{SiO}_{2} \cdot 3 \mathrm{H}_{2} \mathrm{O}+\mathrm{Ca}(\mathrm{OH})_{2}
\end{aligned}
$$

A cement whose hydration produces a high quantity of hydrated lime will react with the amorphous silica of the glass powder to produce the so-called second-generation hydrated calcium silicates leading to more resistant mortars. The occurring reaction is as follows (Eq. 5):

$\underset{\text { portlandite }}{\mathrm{Ca}(\mathrm{OH})_{2}}+\underset{\substack{\text { amorphous } \\ \text { silica }}}{\mathrm{SiO}_{2}}+\underset{\text { water }}{(\mathrm{n}-1) \mathrm{H}_{2} \mathrm{O}} \longrightarrow \underset{\text { C-S-H }}{\mathrm{CaO} \cdot \mathrm{SiO}_{2} \cdot \mathrm{nH}_{2} \mathrm{O}}$

In the case where the hydration produced less hydrated time, the resistances would be less. According to the data of different authors, the amount of glass waste may vary from 10 to $30 \%[11,12]$. Similar results were obtained by Vijayakumar et al. [7], with regard to compressive strength and flexural strength. The authors reported an increase in the flexural strength from $3 \mathrm{~N} / \mathrm{mm}^{2}$ for the OPC to $7 \mathrm{~N} /$ $\mathrm{mm}^{2}$ for $40 \mathrm{wt} \%$ addition of glass powder and the compressive strength increases from $30 \mathrm{~N} / \mathrm{mm}^{2}$ for the OPC to $45 \mathrm{~N} / \mathrm{mm}^{2}$ for $40 \mathrm{wt} \%$ addition, after 28 curing days. Their work also reported an increase in strength after 60 days of cure. Many other authors $[17,21]$ obtained the same results. On the contrary, Matos et al. [6] achieved a reduction in mechanical strength when glass contents increase from 0 to $20 \mathrm{wt} \%$ with $10 \mathrm{wt} \%$ interval, between 7 and 562 days. The divergence of these results is explained by the chemical composition of the binary binder formed. The cement used was CEM I/B-P 42.5R, and the glass used was a mixing of car windscreens, bottle glass and many others

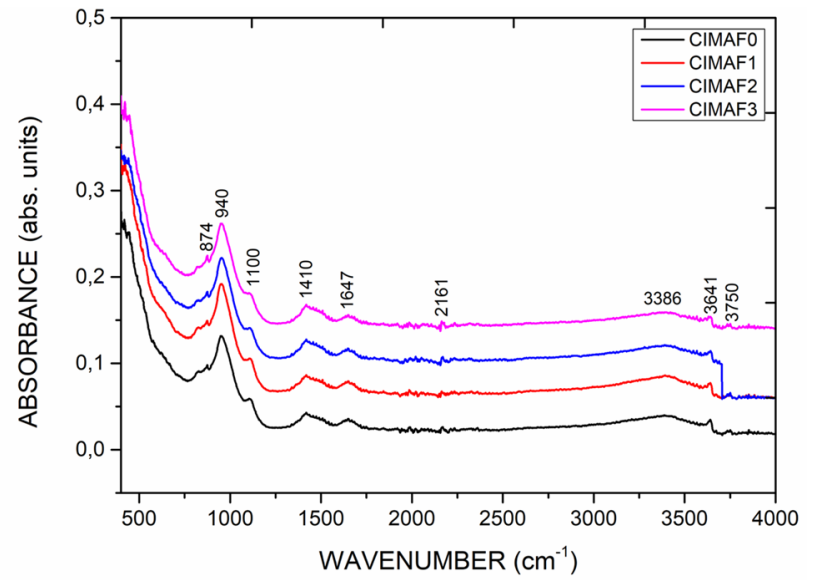

Fig. 5 IR of the cement paste at different percentages substitution

obtained from a recycling glass industry. Glass was also grounded during $48 \mathrm{~h}$ which implies different fitness from the current work.

To easily study microstructural properties of glass powder addition on the cement paste, FTIR, XRD and SEM would be performed on the OPC paste and compared to $5 \mathrm{wt} \%, 10 \mathrm{wt} \%$ and $15 \mathrm{wt} \%$ addition of glass powder on the cement paste, representing the mixtures giving the best mechanical results. Furthermore, the glass powder used would be MGP, considering that the other glass types had the same mechanical strength curve shape (all of them gave the optimum mechanical properties at $10 \mathrm{wt} \%$ addition and mechanical strength considerably increased up to $15 \mathrm{wt} \%$ addition) and the waste glasses are generally obtained from the waste disposal contractors as a mixture of different glass colours.

\subsection{Infrared spectroscopy (IR)}

The FTIR spectra of cement paste with glass powder addition at $0 \%$ (CIMAF0), 5\% (CIMAF1), 10\% (CIMAF2) and 15\% (CIMAF3) are represented in Fig. 5. They were performed after 21 curing days according to XRD and SEM analysis.

The depicted results from Fig. 5 reveal nine almost identical peaks in each spectrum for all of the samples analysed. The peaks at $3750 \mathrm{~cm}^{-1}$ and $3386 \mathrm{~cm}^{-1}$ were, respectively, characteristic to asymmetric stretching vibration of ${ }^{-} \mathrm{OH}$ bond of water molecules and to the stretching band in flexion of the $\mathrm{OH}$ bond due to crystallization of water molecules, in gypsum mineral [14]. The peaks at $3640 \mathrm{~cm}^{-1}$ and $1647 \mathrm{~cm}^{-1}$ meanwhile correspond to the vibration of the $\mathrm{O}-\mathrm{H}$ bond in the portlandite $\left(\mathrm{Ca}(\mathrm{OH})_{2}\right)$. Their intensities decrease slightly between 0 and $15 \%$, of substitution, demonstrating the second-generation pozzolanic reaction occurred. The bands at $2161 \mathrm{~cm}^{-1}$, $1410 \mathrm{~cm}^{-1}$ and $874 \mathrm{~cm}^{-1}$ were assigned to carbonates 
$\left(\mathrm{CO}_{3}{ }^{2-}\right)$ for the reactions between atmospheric $\mathrm{CO}_{2}$ and calcium hydroxide; they therefore determine the presence of calcium carbonate $\left(\mathrm{CaCO}_{3}\right)$. The peak at $1100 \mathrm{~cm}^{-1}$ is due to the $\mathrm{SO}_{4}{ }^{2-}$ radical in the sulphate group, which is characteristic of the presence of ettringite. The elongated shape of the band at $940 \mathrm{~cm}^{-1}$ due to the silicates $\left(C_{2} S\right.$ and $\mathrm{C}_{3} \mathrm{~S}$ ) indicates the development of the hydration of the cement and the formation of $\mathrm{C}-\mathrm{S}-\mathrm{H}$ [15].

\subsection{X-ray diffractometry (XRD)}

X-ray diffractometry was performed on OPC paste (CIMAF0) and on MGP addition in the cement paste at $5 \mathrm{wt} \%$ (CIMAF1), $10 \mathrm{wt} \%$ (CIMAF2) and $15 \mathrm{wt} \%$ (CIMAF3) at the age of 21 days considering the work of Newmann and Choo [16], which determined that some products of the reactions disappeared after 28 days. The results are presented in Fig. 6 . This analysis revealed the presence of ettringite which is obtained from the hydration of $\mathrm{C}_{3} \mathrm{~A}$ following the reaction (Eq. 6):

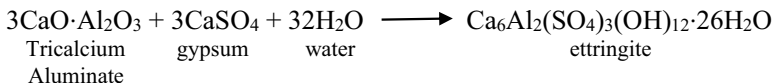

Calcium hydroxide is mainly obtained from the hydration of $\mathrm{C}_{2} \mathrm{~S}$ and $\mathrm{C}_{3} \mathrm{~S}$, hydrated calcium silicate, which are generated by combining the hydration of $\mathrm{C}_{3} \mathrm{~S}, \mathrm{C}_{2} \mathrm{~S}$ and the pozzolanic reaction of glass powder [17], tri-calcium aluminate, calcite and di-calcium aluminate which are the hydration products of Portland cement paste and sodium carbonate provided by the addition of glass powder. We also found between $5^{\circ}$ and $20^{\circ}\left(2\right.$ theta ${ }^{\circ}$ ) the presence of a dome suggesting the existence of amorphous phases, which were related by EDS as calcium silicate hydrate

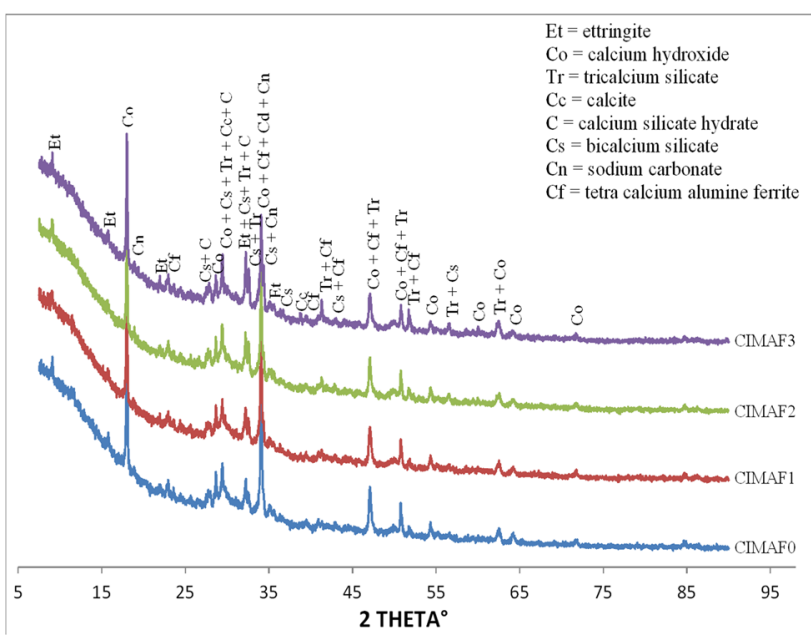

Fig. 6 X-ray diffractometry of the cement paste at different percentages substitution
(CSH) as well as also reported by Elaqra and Rustom [28]. These peaks do not really change from 0 to $15 \mathrm{wt} \%$ substitutions. However, we can still observe the peaks at $23^{\circ}, 28^{\circ}$, $54^{\circ}$ and $71^{\circ}\left(2\right.$ theta $\left.^{\circ}\right)$, which represented that the $\mathrm{C}-\mathrm{S}-\mathrm{H}$ becomes smaller at $15 \mathrm{wt} \% \mathrm{GP}$ addition. This indicates the effect of a pozzolanic reaction which occurred at lower level of substitution and reduced at this stage. The effects are the appearance or the growth as the case may be of tri-calcium silicate peaks intensity at $32^{\circ}, 41^{\circ}, 51^{\circ}, 56^{\circ}$ and $62^{\circ} 2$-theta degrees. Similar results were obtained by Liu et al. [3] reporting that the addition of recycled waste glass reduces the peak intensity of portlandite, ettringite and $C_{2} S, C_{3} S$ with the increasing glass powder amount, while the peaks of $\mathrm{C}-\mathrm{S}-\mathrm{H}$ become clearer having higher intensity. The pozzolanic character of waste glass can also enhance the consumption of calcium hydroxide and calcium silicate, which is related to the reducing peak intensity.

\subsection{Scanning electron microscopy (SEM)}

Scanning electron microscopy (SEM) and energy-dispersive X-ray (EDS) analyses were carried out on the CIMAFO, CIMAF1, CIMAF2 and CIMAF3 paste samples at age 21 days according to XRD. The images obtained are represented in Figs. 7, 8, 9 and 10.

The observation combined with the EDS analysis made it possible to identify the hydrates present in the cement matrix of each formulation, as well as the main structures observed: pores and microcracks.

\subsubsection{Hydrates formation}

As we can observe in Figs. 7 and 8, the main hydrating products on the hydrated paste samples are $\mathrm{C}-\mathrm{S}-\mathrm{H}$ gels in the form of cotton flowers [29], which have good germination in the matrix. Needles are also found in quantity. They are generally identified as ettringite. This results in a good condition of hydration of the cement grains with the presence of glass powders. $C_{4} A F$ (Figs. 7c, 8b), $C_{3} A$ (Fig. 7a) and glass particle (Fig. $8 \mathrm{~d}$ ) showed by EDS have also been identified, but in much smaller quantities. $C_{4} A F$ and $C_{3} A$ are even less present at $15 \mathrm{wt} \%$ substitution. This result can be explained by the amount of water used. In fact, cementitious pastes of different quantities of glass powder are made with the same amount of water. As the amount of cement decreases, the amount of water remains constant; the $W / C$ ratio therefore increases in proportion to the percentage of glass powder. The consequence has increased the hydration at 15 wt $\%$ substitution. Many authors such as Lawrence et al. [30] showed an acceleration of hydration process caused by the presence of mineral additions. The hypothesis put forward is that the internal layer of $\mathrm{C}-\mathrm{S}-\mathrm{H}$ 

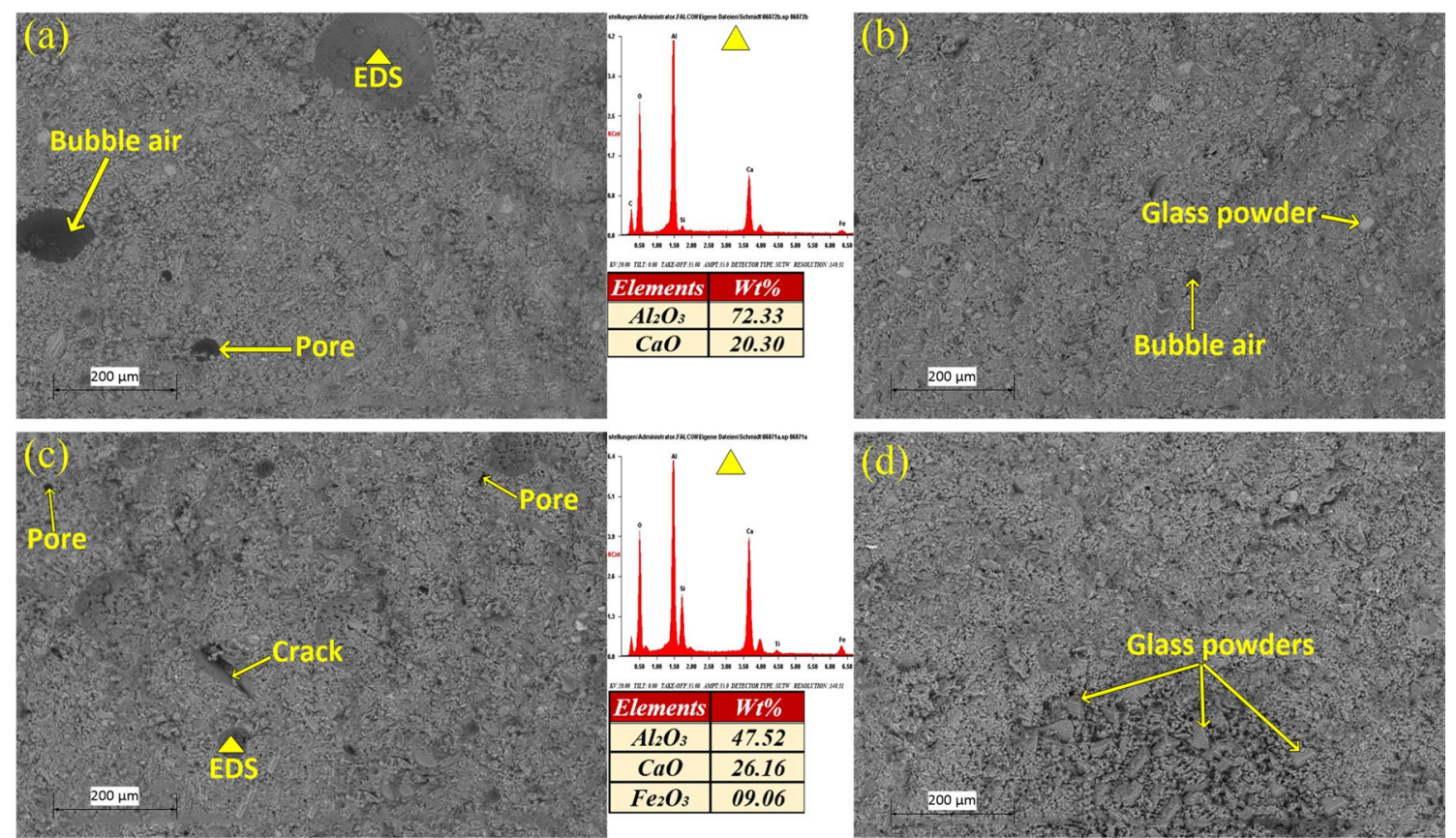

Fig. 7 SEM BSE images and EDS of a CIMAF0, b CIMAF1, c CIMAF3, d CIMAF2 pastes 100 times enlarged
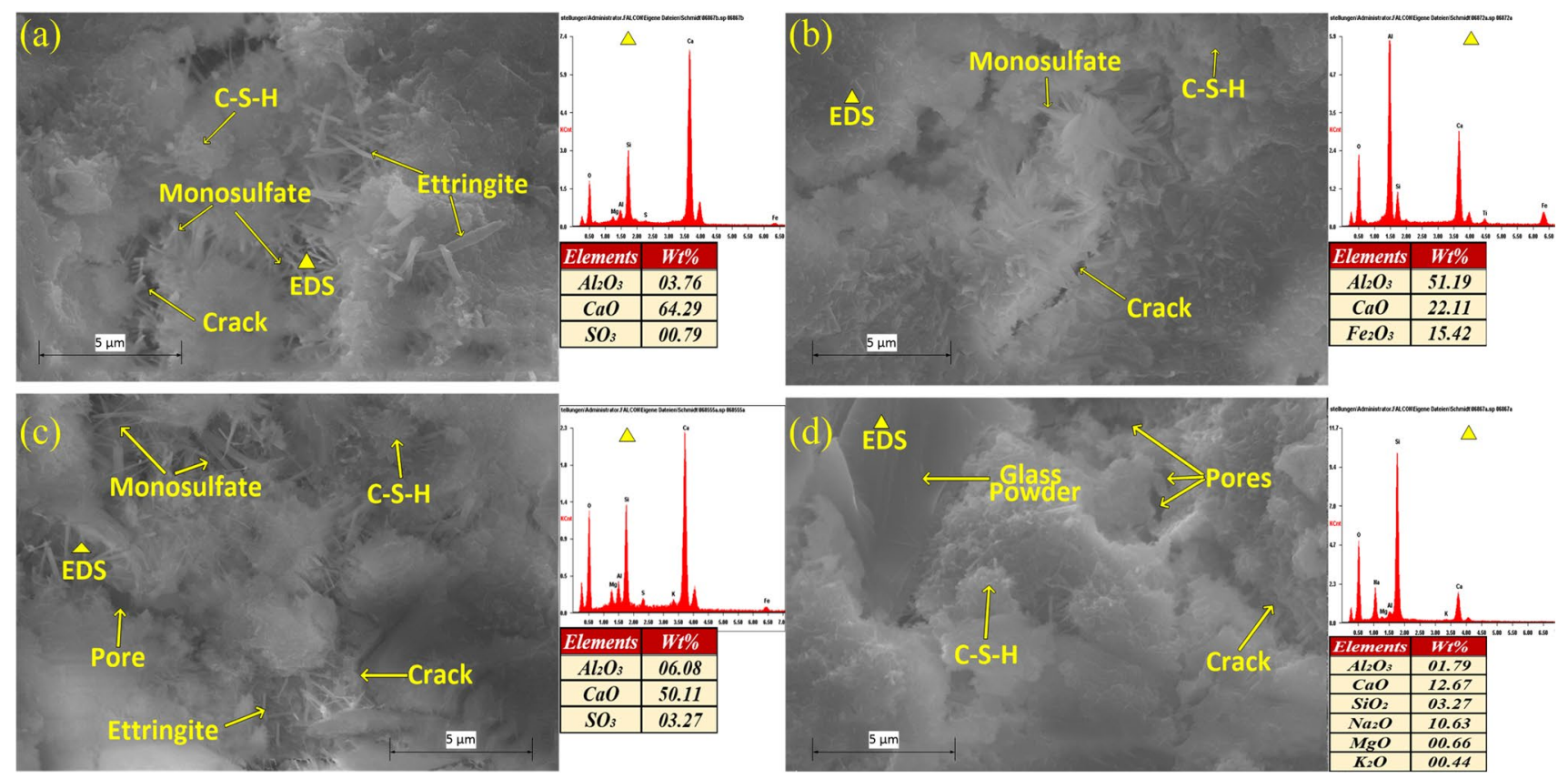

Fig. 8 SEM SE images and EDS of a CIMAF0, c CIMAF2, d CIMAF3 pastes 5000 times enlarged, b CIMAF1 4800 times enlarged

gel formed around the grains of the matrix is thinner in the presence of fine particles and facilitates the diffusion of the anhydrous phases. The cement grains therefore accelerate their hydration processes [1].

At $15 \mathrm{wt} \%$ substitution, there are a greater number of submicron particles in the cement matrix. These particles are placed around the cement grains and multiply the possibilities of germination of hydrated products, and this develops the microstructural complexity and the efficiency of the bonds [31] (Fig. 8d). The $10 \mathrm{wt} \%$ substitution cement matrix is more homogeneous and more compact than the $15 \%$ matrix. This phenomenon is obvious because 

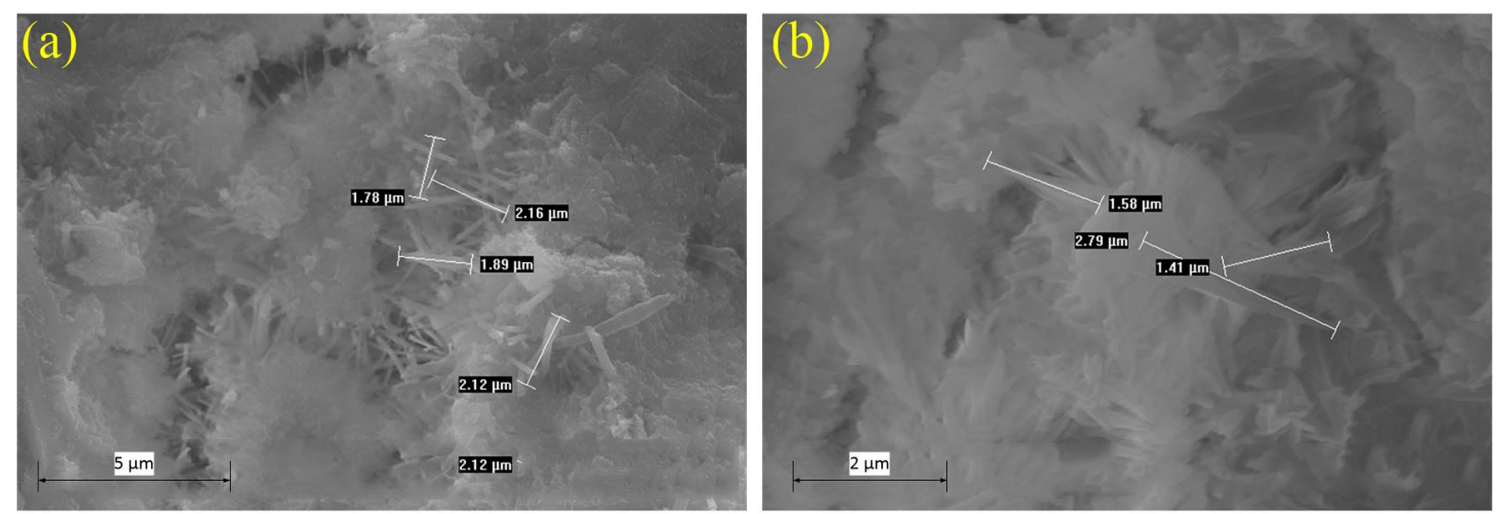

Fig. 9 SEM images of ettringite rods measurement on cement: a CIMAF0 paste 5000 times enlarged, b CIMAF1 10,000 times enlarged
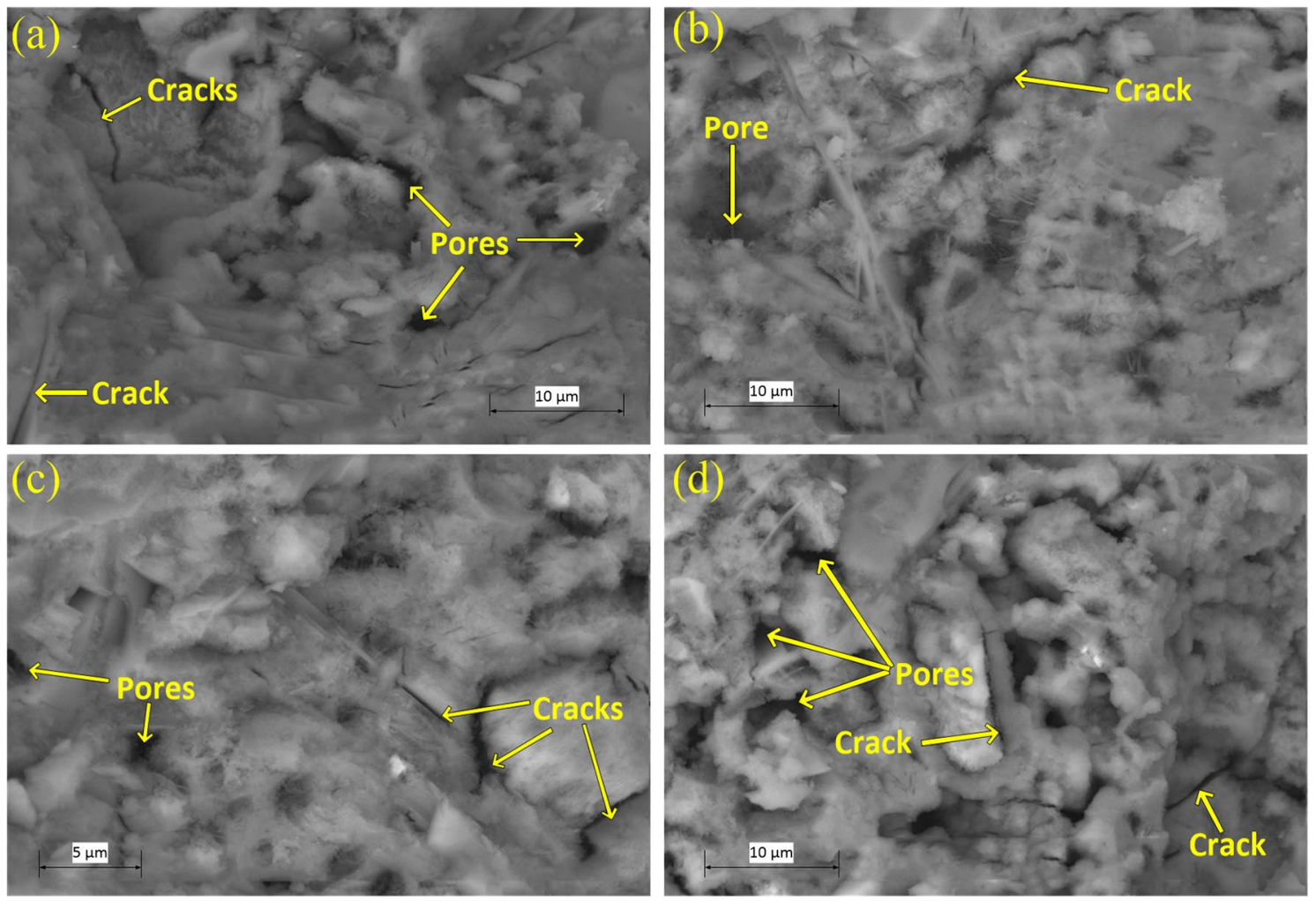

Fig. 10 SEM BSE images of a CIMAF0, b CIMAF1, d CIMAF3 pastes 2000 times enlarged, c CIMAF2 3000 times enlarged

the amount of water remaining in the dough at $15 \mathrm{wt} \%$ substitution is greater than that at $10 \mathrm{wt} \%$ substitution which could explain the strengths obtained.

We also performed measurements on the morphology of needles as presented in Fig. 9. These measurements showed two types of needle. These types are differentiated by their forms and their length. On the one hand, they are needle which are straight; and their length varies from 1.41 to $1.89 \mu \mathrm{m}$. On the other hand, some needles are twisted and their length varies from 2.12 to $2.79 \mu \mathrm{m}$. The EDS performed on some points (Fig. 8a, c) of the cement paste matrix revealed the presence of monosulphate which is formed following the reaction (Eq. 7): 


$$
\begin{aligned}
& \mathrm{Ca}_{6} \mathrm{Al}_{2}\left(\mathrm{SO}_{4}\right)_{3}(\mathrm{OH})_{12} \cdot 26 \mathrm{H}_{2} \mathrm{O}+2\left(3 \mathrm{CaO} \cdot \mathrm{Al}_{2} \mathrm{O}_{3}\right)+4 \mathrm{H}_{2} \mathrm{O} \longrightarrow \mathrm{CaO} \cdot \mathrm{Al}_{2} \mathrm{O}_{3} \cdot \mathrm{CaSO}_{4} \cdot 12 \mathrm{H}_{2} \mathrm{O}(\mathrm{Eq} 7) \\
& \text { Ettringite tricalcium water monosulfate } \\
& \text { aluminate }
\end{aligned}
$$

The hypothesis that can be formulated is that the long length twisted needles are ettringite and the straight needles are monosulphate, according to Newmann and Choo [16], which determined volume\% of monosulphate at 28 days as $16 \%$, while volume $\%$ of ettringite at the same age was $0 \%$. In fact, we can observe much more straight needles than long length twisted needles.

\subsubsection{The pores}

Capillary porosity, as observed in Fig. 10, results from the voids left by the water consumed by hydration. The size of the capillary pores varied between $10 \mathrm{~nm}$ and $15 \mu \mathrm{m}$. Therefore, the pores between $0.05 \mathrm{~nm}$ and $15 \mu \mathrm{m}$ influence the mechanical strength and the permeability to water vapour [1]. Observation of the microstructure reveals a relatively large capillary porosity as the percentage of addition increases. These pores are identifiable by variations in the grey level in the images. Indeed, the pores are the darkest areas. At $15 \mathrm{wt} \%$ substitution, we get a larger distribution of pores than $10 \mathrm{wt} \%$ and $5 \mathrm{wt} \%$ and significantly more than $0 \mathrm{wt} \%$. This is due to the increase in the $W / C$ ratio in proportion to the addition of glass powder as noted above. Thus, as some authors have noted [32, 33], the greater the hydration the more the matrix is porous.

\subsubsection{Microcracks}

The mechanical strength of cementitious materials strongly depends on the inter-material bonds in the matrix [34-37]. It can be noted that the $\mathrm{C}-\mathrm{S}-\mathrm{H}$ gels cover almost the entire surface of the cement matrices studied. This proves a good bond between the cement paste and the unreacted glass particles. No cracks visible to the naked eye were found. On the other hand, we can observe microcracks on the interface between the cement paste and the glass particles as presented in Fig. 10. Because of the heterogeneity of the matrix, the positions as well as the sizes of the cracks are very variable. Similar results were obtained by Nguyen [1] about addition of glass powder on the cement paste.

\section{Conclusion}

The purpose of this study was to determine the mechanical and microstructural behaviour of CPJ NC CEM II/B-P $42.5 \mathrm{R}$ cement with the addition of glass powder of three different types and the mixing of these glass powders, in order to highlight the influence of glass powder as a cement substitute for the class defined above. To carry out this work, the analyses performed were: setting time, flexural strength, compressive strength, infrared spectroscopy, $\mathrm{X}$-ray diffractometry and scanning electron microscopy coupled with EDS.

The results showed that setting time increased with the increase in glass powder addition on cement paste. The addition of glass powders up to $25 \mathrm{wt} \%$ showed also an increase in the flexural strength. With regard to the compressive strength, up to $20 \mathrm{wt} \%$ addition, regardless of the colour of glass, sample tested gave better strength than OPC mortar. The FTIR spectra study showed the vibration of the $\mathrm{O}-\mathrm{H}$ bond in the portlandite $\left(\mathrm{Ca}(\mathrm{OH})_{2}\right)$. Their intensities decreased slightly between 0 and $15 \%$, of substitution, demonstrating the second-generation pozzolanic reaction occurred. The XRD revealed the presence of ettringite, calcium hydroxide, tri-calcium aluminate, calcite, hydrated calcium silicate, di-calcium aluminate on all samples and sodium carbonate added by the addition of glass powder. As for the microstructure, SEM revealed that $\mathrm{C}-\mathrm{S}-\mathrm{H}$ gels cover almost the entire surface of the cement paste and microcracks can be observed on the interface between the cement paste and the glass powder particles. $\mathrm{C}-\mathrm{S}-\mathrm{H}$ and needles were easily observed, but some other products such as $C_{4} A F, C_{3} A$ and monosulphate are needed to perform EDS to be identified. The measurements made on the needles show that there are two types of needles distinguished by their length and their form. Long length twisted needles were identified as ettringite, and straight needles in larger quantity identified as monosulphate.

In the end, the results show a significant role played by the glass powder in the cement paste. It was concluded that white glass powder addition gave the best flexural strength. The best compressive strength was obtained with green glass powder. Regardless of the colour of glass, the optimal content of substitution of CPJ NC CEM II/B-P 42.5 cement in the OPC mortar, considering mechanical properties, is $10 \mathrm{wt} \%$. This study benefits from its contribution to the recycling of glass waste as a cement additive and at the same time promotes the use of environmentally friendly materials in construction thanks to the results obtained. 


\section{Compliance with ethical standards}

Conflict of interest The authors declare that they have no competing interests.

\section{References}

1. Nguyen H (2013) Valorisation du verre dans le béton Etude expérimentale du comportement de pâte de ciment et du mortier: rhéologie, mécanique et durabilité. Thèse de doctorat en cotutelle. Université d'Aix-Marseille, Institut de mécanique du Viet Nam, p 119. http://www.theses.fr/2013AIXM4793/document

2. Bueno ET, Paris JM, Clavier KA, Spreadbury C, Ferraro CC, Townsend TG (2020) A review of ground waste glass as a supplementary cementitious material: a focus on alkali-silica reaction. J Clean Prod. https://doi.org/10.1016/j.jclepro.2020.12018 0

3. Liu G, Florea MVA, Brouwers HJH (2019) Performance evaluation of sustainable high strength mortars incorporating high volume waste glass as binder. Constr Build Mater 202:574-598

4. Aliabdo AA, Elmoaty AMAE, Aboshama AY (2016) Utilization of waste glass powder in the production of cement and concrete. Constr Build Mater. https://doi.org/10.1016/j.conbuildma t.2016.08.016

5. Rodier L, Savastano H (2018) Use of glass powder residue for the elaboration of eco-efficient cementitious materials. J Clean Prod. https://doi.org/10.1016/j.jclepro.2018.02.269

6. Matos AM, Sousa-Coutinho J (2012) Durability of mortar using waste glass powder as cement replacement. Constr Build Mater 36:205-215

7. Vijayakumar G, Vishaliny H, Govindarajulu D (2013) Studies on glass powder as partial replacement of cement in concrete production. Int J Emerg Technol Adv Eng 3(2):153-157

8. Pike RG, Hubbard ND, Binary ES (1960) Silicate glasses in the study of alkali-aggregate reaction. Highw Res Board Bull 275:39-44

9. Schmidt A, Saia WHF (1963) Alkali-aggregate reaction tests on glass used for exposed aggregate wall panel work. ACI Mater J 60:1235-1236

10. Pattengil M, Shutt TC (1973) Use of ground glass as a pozzolan. In: Albuquergue symposium on utilisation of waste glass in secondary products, Albuquerque, NM, USA, pp 137-153

11. Xie Z, Xi Y (2002) Use of recycled glass as a raw material in the manufacture of Portland cement. Mater Struct 35:510-515

12. Schwarz N, Neithalath N (2008) Influence of a fine glass powder on cement hydration: comparison to fly ash and modelling the degree of hydration. Cem Concrete Res 38(4):429-436

13. Hwang CL, Shen DH (1991) The effects of blast-furnace slag and fly ash on the hydration of Portland cement. Cem Concr Res 21(4):410-425

14. Vaičiukynienè $D$, Skipkiūnas $G$, Daukšys $M$, Sasnauskas V (2013) Cement hydration with zeolite-based additive. Chemija 24(4):271-278

15. Govindarajan D, Gopalakrishnan R (2011) Spectroscopic studies on Indian Portland cement hydrated with distilled water and sea water. Front Sci 1(1):21-27

16. Newmann J, Choo BS (2003) Advanced concrete technology, constituent materials. Department of Civil Engineering Imperial College, Elsevier, London, p 280 (ESBN 07506511032)
17. Abdullah A (2016) The influence of waste glass powder as a pozzolanic material in concrete. Int J Civ Eng Technol 7(6):131-148

18. Shi C, Zheng K (2007) A review on the use of waste glasses in the production of cement and concrete. Resour Conserv Recycl 52(2):234-247

19. Shao Y, Lefort T, Moras S, Rodriguez D (2000) Studies on concrete containing ground waste glass. Cem Concr Res 30(1):91-100

20. Chen $\mathrm{CH}$, Huang $\mathrm{R}$, Wu JK, Yang CC (2006) Waste E-glass particles used in cementitious mixtures. Cem Concr Res 36(3):449-456

21. Batayneh M, lqbal M, Asi I (2007) Use of selected waste materials in concrete mixes. Waste Manag 27(12):1870-1876

22. Shayan A, Xu A (2004) Value-added utilisation of waste glass in concrete. Cem Concr Res 34(1):81-89

23. Correia S, Souza F, Dienstmann G, Segadaes AM (2009) Assessment of the recycling potential of fresh concrete waste using a factorial design of experiments. Waste Manag 29(11):2886-2891

24. Sobolev K, Turker P, Soboleva S, Iscioglu G (2007) Utilization of waste glass in ECO-cement: strength properties and microstructural observations. Waste Manag 27(7):971-976

25. Jin C, Meyer C, Baxter S (2000) "Glasscrete"-concrete with glass aggregate. ACI Mater J 97(2):208-213

26. Yamada K, Ishiyama S (2005) Maximum dosage of glass cullet as fine aggregate in mortar. Ach Sustain Constr. https://doi. org/10.1680/asic.34044.0022

27. Bazant ZKP, Zi G, Meyer C (2000) Fracture mechanics of ASR in concretes with waste glass particles of different sizes. J Eng Mech 126(3):226-232

28. Elaqra H, Rustom R (2018) Effect of using glass powder as cement replacement on rheological and mechanical properties of cement paste. Constr Build Mater 179:326-335

29. Li G, Zhao X (2003) Properties of concrete incorporating fly ash and ground granulated blast-furnace slag. Cem Concr Compos 25(3):293-299

30. Lawrence $P, C y r$ M, Ringot E (2003) Mineral admixtures in mortars effect of inert materials I short-term hydration. Cem Concr Res 33(10):1939-1947

31. Bessa A, Bigas JP, Gallias JL (2004) Méthode d'évaluation de l'effet des additions minérales sur le besoin en eau et l'adjuvantation des mortiers. Revue Française de Génie Civil 8(2-3):181-201

32. Tasong WS, Cripps JC, Lynsdale CJ (1998) Aggregate-cement chemical interactions. Cem Concr Res 28(7):1037-1048

33. Prokopski G, Halbiniak J (2000) Interfacial transition zone in cementitious materials. Cem Concr Res 30(4):579-583

34. Rao GA, Prasad BKR (2002) Influence of the roughness of aggregate surface on the interface bond strength. Cem Concr Res 32(2):253-257

35. Elices M, Rocco CG (2008) Effect of aggregate size on the fracture and mechanical properties of a simple concrete. Eng Fract Mech 75(13):3839-3851

36. Kondraivendhan B, Divsholi BS, Teng S (2013) Estimation of strength, permeability and hydraulic diffusivity of pozzolana blended concrete trough pore size distribution. J Adv Concr Technol 11(9):230-237

37. Hongjian D, Kiang HT (2014) Waste glass powder as cement replacement in concrete. J Adv Concr Technol 12(11):468-477

Publisher's Note Springer Nature remains neutral with regard to jurisdictional claims in published maps and institutional affiliations. 